\title{
PENGEMBANGAN MASTERPLAN SISTEM INFORMASI UNIVERSITAS PENDIDIKAN GANESHA SINGARAJA MENGGUNAKAN FRAMEWORK WARD PEPPARD
}

\author{
I Komang Adi Paramarta, Ida Ayu Dwi Giriantari, Made Sudarma \\ Magister Teknik Elektro/Program Pasca Sarjana Universitas Udayana \\ Denpasar, Indonesia \\ komangadi602@gmail.com, dayu.giriantari@unud.ac.id, msudarma@unud.ac.id
}

\begin{abstract}
Abstrak
Universitas Pendidikan Ganesha Singaraja sebagai salah satu lembaga pendidikan tinggi yang akan menuju ke arah E-University telah memanfaatkan sistem informasi dan teknologi informasi dalam menjalankan proses bisnisnya. Diperlukan sebuah Masterplan Sistem Informasi sebagai model pengembangan sistem informasi dan teknologi informasi kedepan yang dihasilkan dari proses analisa menyeluruh terhadap proses bisnis yang ada sehingga tidak ada lagi implementasi sistem informasi yang hanya bersifat situasional dan hanya mengikuti saran dari penyedia barang dan jasa tanpa berdasarkan kebutuhan terhadap proses bisnis yang ada.

Masterplan sistem informasi yang dikembangkan dalam penelitian ini menggunakan kerangka kerja Ward \& Peppard dalam proses analisanya. Dari proses analisa yang dilakukan maka diperoleh kondisi current sistem informasi di Undiksha seperti terdapat beberapa sistem informasi yang masih bersifat statis, hanya berbasis aplikasi desktop, belum terintegrasi dengan aplikasi yang terkait dan belum menunjang proses bisnis secara menyeluruh maka dihasilkan masterplan sistem informasi Universitas Pendidikan Ganesha Singaraja yang berisikan future sistem informasi yang mencakup seluruh proses bisnis di Undiksha, bersifat dinamis, berbasis online dan terintegrasi antar sistem terkait. Future sistem informasi yang dihasilkan sudah mencakup proses bisnis utama seperti promosi (official website, sipro, sippgu), penerimaan mahasiswa baru (sirimam), registrasi perkuliahan (siak), proses belajar mengajar (sivle, siap4k, silab, sipus), evaluasi (sievani, silea, siedos), wisuda (siwis, sipus, siak, siacc) dan mencakup proses bisnis pendukung seperti pengelolaan SDM (simadam), pengelolaan sarana prasarana (siproc, siventi), pengelolaan keuangan (sipeka, sirem, GPPsatker, siakun, SAS), pengelolaan teknologi informasi (siatal), dan evaluasi bisnis (sies, simas).
\end{abstract}

Kata Kunci : Universitas Pendidikan Ganesha, Framework Ward \& Peppard, Masterplan Sistem Informasi.

\begin{abstract}
Ganesha University of Education Singaraja as one of the higher education institutions that will lead to the E-University has utilized information systems and information technology in running its business processes. Thus, an Information System Masterplan is required as a model for information systems development and information technology in the future resulted from a through analysis process of existing business processes, so that there will be no more merely situational implementation of information systems which only follows the order of the goods and services providers without considering the real needs of the existing business processes.

The information system masterplan developed in this study uses the Ward \& Peppard framework in its analytical process. From the process of analysis was then obtained the current condition of the information systems in Undiksha e.g. there are some information systems that are still static-only based on desktop applications, and was not yet integrated with related applications and did not yet support the business process thoroughly. Therefore, the masterplan of the information system will contain the future information systems that cover all business processes in Undiksha, such as promotion (official website, sipro, sippgu), new students enrolment (sirimam), class registration (siak), learning process (sivar, siap4k, syllabus, sipus), evaluation (sievani, silea, siedos), graduation (siwis, sipus, siak, siacc ) and includes supporting business processes such as human resources management (simadam), infrastructure management (siproc, siventi), financial management (sipeka, sirem, GPPsatker, siakun, SAS), management of information technology (siatal), and business evaluation (sies, simas ).
\end{abstract}


Keywords: Ganesha University of Education, Ward \& Peppard Framework, Masterplan of Information System.

\section{PENDAHULUAN}

Saat ini seiap organisasi sudah memanfaatkan teknologi informasi dalam menjalankan usahanya. Tetapi banyak organisasi yang membuat keputusan tentang pemanfaatan teknologi informasi hanya berdasarkan apa yang mereka percaya dan rekomendasi dari kolega atau vendor tanpa melakukan perencanaan secara menyeluruh dan mandiri terhadap kebutuhan-kebutuhan sistem informasi yang diperlukan sehingga terjadi pemanfaatan teknologi informasi yang tidak efektif. Universitas Pendidikan Ganesha (UNDIKSHA) sebagai salah satu lembaga pendidikan tinggi yang memiliki nafas pendidikan dalam rangka menghasilkan para calon guru sudah saatnya menerapkan ICT (Information Communication \& Technology) yang terencana secara strategis dalam membantu proses belajar mengajar, meningkatkan mutu dan layanan pendidikan maupun dalam tata kelola. Dari latar belakang tersebut dapat dijabarkan sebuah rumusan masalah yaitu Bagaimanakah Masterplan Sistem Informasi Universitas Pendidikan Ganesha Singaraja Menggunakan Framework Ward And Peppard?. Adapun tujuan yang ingin dicapai dalam penelitian ini adalah Dihasilkan masterplan sistem informasi di Universitas Pendidikan Ganesha berupa strategi dan program kerja pengembangan sistem informasi (SI) dan teknologi informasi (TI), desain sistem informasi proses bisnis, portofolio future sistem informasi, portal layanan yang dikembangkan, GAP analisis, dan rencana implementasi sistem informasi jangka 5 tahun.

Sistem informasi (SI) merupakan suatu sistem buatan manusia yang secara umum terdiri atas sekumpulan komponen berbasis komputer dan manual yang dibuat untuk menghimpun, menyimpan, dan mengelola data serta menyediakan informasi keluaran kepada para pemakai (Gelinas, Oram, dan Wiggins 1990, as cited in Kadir, 2003). Sedangkan teknologi informasi mencakup perangkat keras dan perangkat lunak untuk melaksanakan satu atau sejumlah tugas pemrosesan data seperti menangkap, mentransmisikan, menyimpan, mengambil, memanipulasi, atau menampilkan data (Alter, 1991, as cited in Kadir, 1003). Strategi sistem informasi menekankan pada penentuan aplikasi sistem informasi yang dibutuhkan organisasi. Esensi dari strategi SI adalah menjawab pertanyaan "apa?". Sedangkan strategi $\mathrm{TI}$ lebih menekankan pada pemilihan teknologi, infrastruktur dan keahlian khusus yang terkait atau menjawab pertanyaan "bagaimana? Menurut Ward dan Peppard (1001) terdapat beberapa alasan suatu organisasi memerlukan strategi sistem informasi yaitu : (1) Adanya investasi untuk pengadaan $\mathrm{SI} / \mathrm{TI}$ yang tidak mendukung sasaran bisnis suatu organisasi, (2) SI/TI yang ada tidak terkontrol, (3) Sistem tidak teintegrasi, (4) Organisasi tidak memiliki skala prioritas dalam mengembangkan proyek $\mathrm{SI} / \mathrm{TI}$, sehingga sangat sering terjadi perubahan dan tambal sulam yang akhirnya menurunkan produktivitas organisasi, (5) Manajemen informasi yang buruk dan tidak akurat, (6) Strategi SI/TI tidak sejalan dengan strategi bisnis organisasi, (7) Proyek SI/TI hanya dievaluasi untuk kepentingan keuangan semata. Menurut Ward and Peppard (2002), Perencanaan strategis $\mathrm{SI} / \mathrm{TI}$ merupakan proses identifikasi portfolio aplikasi SI berbasis komputer yang akan mendukung organisasi dalam pelaksanaan rencana bisnis dan merealisasikan tujuan bisnisnya. Analisis dilakukan terhadap empat aspek yaitu

1. Lingkungan internal bisnis menggunakan teknik analisis:

Value chain yang menjabarkan aktivitas utama dan pendukung bisnis, critical success factors yang menganalisis beberapa hal yang menjadi fokus dalam menentukan sukses tidaknya sebuah proses bisnis, SWOT yang menjabarkan apa yang menjadi kekuatan kelemahan 
kesempatan dan ancaman dalam menjalankan proses bisnis.

2. Lingkungan eksternal bisnis menggunakan teknik analisis:

analisis five forces yang menjelaskan lima titik ancaman dari luar yang dapat mempengaruhi proses bisnis, dan analisis PEST yang menjabarkan beberapa hal terkait kondisi politik ekonomi sosial teknologi yang ada saat ini.

3. Lingkungan internal SI/TI menggunakan teknik analisis McFarlan portofolio yang menjabarkan dengan matrik kondisi current sistem informasi dan future sistem informasi.

4. Lingkungan eksternal $\mathrm{SI} / \mathrm{TI}$ yang menjabarkan perkembangan teknologi saat ini yang mungkin dapat mendukung perkembangan SI/TI di Undiksha.

Gambar 1 berikut ini menunjukkan model perencanaan strategis sistem informasi menggunakan framework Ward and Peppard:

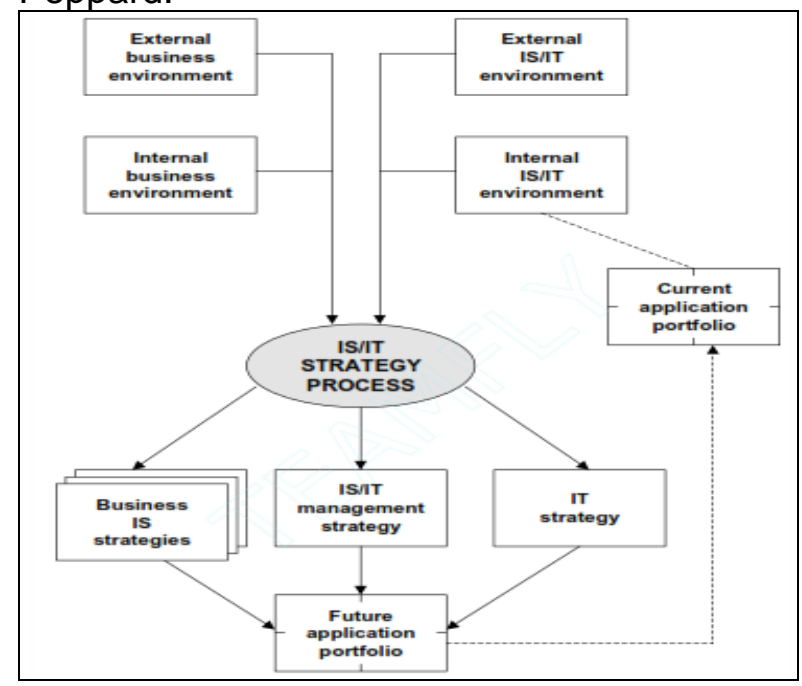

Gambar 1. Model Perencanaan Strategis Sistem Informasi

\section{METODE}

Dalam pengembangan sebuah sistem informasi umumnya terdiri dari input, proses, dan output. Dalam alur penelitian ini juga terdapat input, proses, dan output seperti dijelaskan berikut ini:

1. Input. Terdiri dari perumusan masalah, studi literatur, pengumpulan data (observasi, kuesioner, wawancara, dan dokumentasi), dan tabulasi data. Jika data yang terkumpul dirasa sudah cukup maka dilanjutkan ke tahapan proses data, jika data yang ada dirasa belum cukup maka akan kembali ke tahapan input data.

2. Proses. Data yang sudah terkumpul dan dirasa cukup untuk dilanjutkan ke tahapan selanjutnya akan diolah dengan diawali proses pengujian data yaitu uji validitas data, uji reliabilitas data, dan uji kredibilitas data, hal itu dilakukan agar data yang dianalisis sudah valid, reliable, dan kredibel. Tahapan berikutnya melakukan analisa data menggunakan pendekatan Ward and Peppard yaitu analisis lingkungan eksternal bisnis (teknik analisis five forces dan PEST), analisis lingkungan internal bisnis (teknik analisis SWOT, value chain, CSFs), analisis eksternal $\mathrm{SI} / \mathrm{TI}$, dan analisis internal $\mathrm{SI} / \mathrm{TI}$ (analisis portofolio aplikasi). Proses analisis data menghasilkan strategi SI bisnis, strategi $\mathrm{SI} / \mathrm{TI}$ manajemen, dan strategi TI.

3. Output. Berupa Masterplan Sistem Informasi Universitas Pendidikan Ganesha Singaraja yang berisikan program kerja, future portofolio sistem informasi, kriteria sistem informasi, fungsi dan unit pengguna sistem informasi, GAP analisis antara current dengan future sistem informasi, rencana implementasi sistem informasi dalam jangka 5 tahun, dan disain TI dengan future arsitektur jaringannya. Jenis data dalam penelitian ini yaitu : (1) Data primer yang merupakan data yang bersifat kuantitatif dan kualitatif, seperti data langsung dari responden dalam bentuk kuesioner untuk data primer kuantitatif dan data mengenai proses bisnis dilokasi penelitian dari sumber langsung pelaku proses bisnis di lokasi penelitian untuk data primer kualitatif seperti proses administrasi umum, kemahasiswaan, akademik, dan data kondisi SI/TI saat ini. (2) Data sekunder hanya bersifat kualitatif dimana yang menjadi sumber datanya adalah literatur, artikel, jurnal serta situs di internet yang berkenaan dengan penelitian yang dilakukan, seperti data visi dan misi serta kelembagaan Universitas Pendidikan Ganesha. Tabel 1 berikut ini menampilkan sumber data 
Tabel 1. Jenis dan Sumber Data Penelitian

\begin{tabular}{|l|l|}
\hline \multicolumn{1}{|c|}{ Jenis Data } & \multicolumn{1}{c|}{ Sumber Data } \\
\hline Visi misi tujuan strategi dan program organisasi & BUK dan website Undiksha \\
\hline Profil dan struktur organisasi & BUK dan website Undiksha \\
\hline Data mahasiswa dan proses bisnis utama & BAK dan website Undiksha \\
\hline Data kepegawaian & BUK \\
\hline Data proses bisnis pendukung & BUK \\
\hline Data sarana prasarana & BUK \\
\hline Kondisi SI/TI & Unit TIK \\
\hline Data proses bisnis di Fakultas & Fakultas \\
\hline Data Perpustakaan & Perpustakaan \\
\hline Data Penelitian & LPPM dan LP3M \\
\hline
\end{tabular}

Pengumpulan data penelitian dilakukan dengan metode Observasi langsung ke sumber data, kuesioner pemanfaatan $\mathrm{SI} / \mathrm{TI}$ di internal Undiksha, wawancara kepada pelaku proses bisnis di Undiksha, dan dokumentasi kondisi SI/TI di Undiksha. Identifikasi terhadap proses bisnis utama yang ada di Undiksha menghasilkan proses bisnis seperti gambar 3 berikut ini:

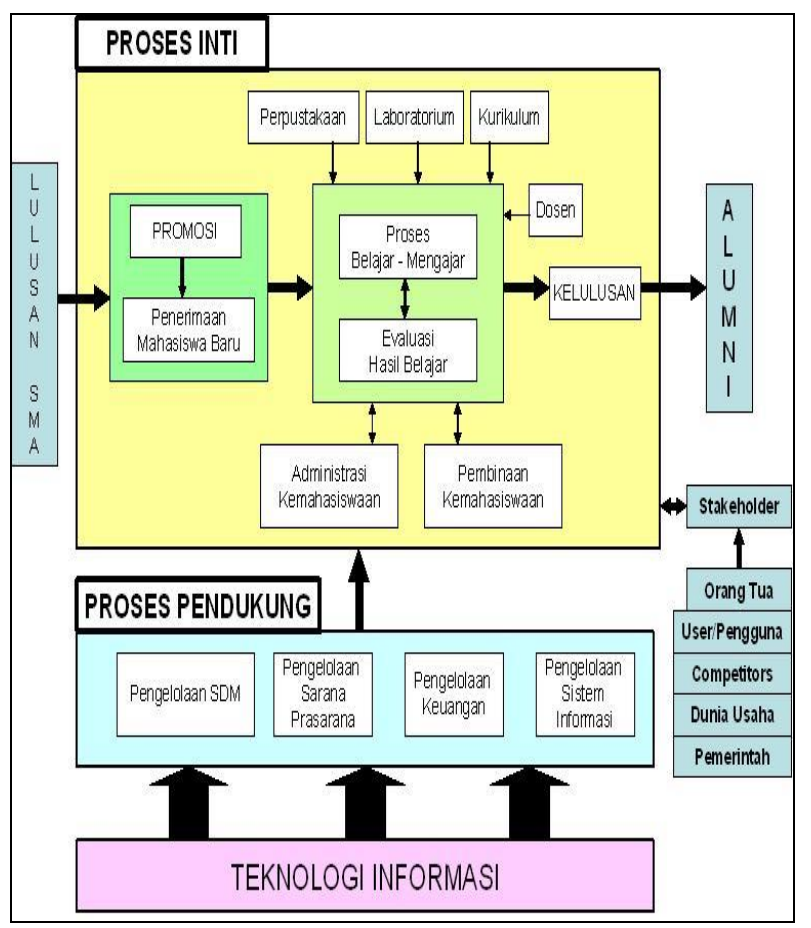

Gambar 3. Proses Bisnis
Hasil observasi yang dilakukan peneliti tentang kondisi jaringan yang ada di Undiksha saat ini adalah : (1) Kapasitas jaringan internet Undiksha sebesar 300Mbps, (2) Jaringan LAN tersebar pada setiap bagian/unit/fakultas, (3) Kabel UTP digunakan untuk distribusi jaringan lokal dan internet pada setiap ruangan/bagian, (4) Kabel fiber optic digunakan untuk distribusi jaringan internet dari kantor pusat TIK kepada setiap fakultas/unit/lembaga, (5) Pada kantor pusat TIK terdapat server sebagai pusat data yaitu web server, mail server, dns server, dan database server, (6) Pada setiap unit/fakultas/lembaga terdapat switch/hub untuk distribusi jaringan, radio wifi untuk menangkap sinyal wireless, dan pemancar wifi untuk memancarkan sinyal internet.

Peneliti melakukan proses identifikasi terhadap sistem informasi/aplikasi yang ada di Undiksha saat ini bertujuan untuk mengetahui current aplikasi yang akan dijadikan tolak ukur dalam mengembangkan future aplikasi dimana merupakan bagian penting dari masterplan SI/TI di Undiksha. Sistem informasi yang ada di Undiksha saat ini yang mendukung proses bisnis utama dan pendukung seperti tabel 2 berikut ini:

Tabel 2. Sistem Informasi di Undiksha

\begin{tabular}{|l|c|c|}
\hline Sistem Informasi & Pengguna & Keterangan \\
\hline SIAK & Mahasiswa dan Dosen & Sistem informasi tentang aktifitas \\
\hline
\end{tabular}




\begin{tabular}{|l|l|l|}
\hline SI Perpustakaan & $\begin{array}{l}\text { Mahasiswa, Pegawai, } \\
\text { Dosen }\end{array}$ & $\begin{array}{l}\text { Sistem informasi tentang aktifitas } \\
\text { kepustakaan }\end{array}$ \\
\hline Official web & $\begin{array}{l}\text { Mahasiswa, Pegawai, } \\
\text { Dosen, dan Masyarakat } \\
\text { Umum }\end{array}$ & $\begin{array}{l}\text { Portal utama Undiksha yang berisi } \\
\text { informasi tentang Undiksha }\end{array}$ \\
\hline SI Kepegawaian & Pegawai dan Dosen & $\begin{array}{l}\text { Sistem informasi tentang aktifitas } \\
\text { kepegawaian dosen dan pegawai } \\
\text { Undiksha }\end{array}$ \\
\hline $\begin{array}{l}\text { SI } \\
\text { Inventarisasi/SIMAK- } \\
\text { BMN }\end{array}$ & Pegawai & $\begin{array}{l}\text { Sistem informasi tentang persediaan dan } \\
\text { barang milik negara yang ada di Undiksha }\end{array}$ \\
\hline SI Penelitian DIPA & Pegawai dan Dosen & $\begin{array}{l}\text { Sistem informasi tentang administrasi } \\
\text { Penelitian DIPA }\end{array}$ \\
\hline E-Journal & Dosen dan Mahasiswa & Sistem informasi journal \\
\hline E-Learning & Dosen dan Mahasiswa & $\begin{array}{l}\text { Sistem informasi pembelajaran secara } \\
\text { online }\end{array}$ \\
\hline SiPePeng & Pegawai dan Dosen & $\begin{array}{l}\text { Sistem informasi perencaan dan realisasi } \\
\text { anggaran }\end{array}$ \\
\hline GppSatker & Pegawai & Aplikasi administrasi belanja pegawai \\
\hline SAS & Pegawai & Aplikasi administrasi pengajuan dana \\
\hline SAK-BLU & Pegawai & Aplikasi Pelaporan Dana BLU \\
\hline
\end{tabular}

\section{HASIL DAN PEMBAHASAN}

Analisis data dilakukan sesuai dengan framework Ward and Peppard sebagai dasar penyusunan masterplan yaitu:
1. Analisis lingkungan internal bisnis menggunakan teknik analisis value chain, CSFs, dan SWOT dengan hasil seperti tabel 3 berikut:

Tabel 3. Hasil Analisis SWOT

\begin{tabular}{|c|c|c|}
\hline EKTERNAL & $\begin{array}{l}\text { Strength } \\
\text { 1. UNDIKSHA adalah satu- } \\
\text { satunya LPTK negeri yang } \\
\text { ada di Bali. } \\
\text { 2. Tenaga pengajar } \\
\text { berpendidikan S2/S3. }\end{array}$ & $\begin{array}{l}\text { Weakness } \\
\text { 1. Sarana dan prasarana } \\
\text { penunjang pendidikan } \\
\text { masih belum memadai } \\
\text { 2. Sistem manajemen } \\
\text { akademik masih perlu } \\
\text { ditingkatkan. }\end{array}$ \\
\hline $\begin{array}{l}\text { Opportunity } \\
\text { 1. Terbukanya peluang untuk } \\
\text { mendapatkan dana penelitian dari } \\
\text { dalam maupun luar negeri. } \\
\text { 2. Terbukanya peluang yang luas bagi } \\
\text { kegiatan pertukaran dosen dan } \\
\text { mahasiswa dengan perguruan } \\
\text { tinggi luar negeri. }\end{array}$ & $\begin{array}{l}\text { Strategi SO } \\
\text { 1. Menjalin kerjasama } \\
\text { (kemitraan) dengan dunia } \\
\text { usaha. } \\
\text { 2. Membentuk Link and } \\
\text { Match antara dunia } \\
\text { kampus dengan dunia } \\
\text { usaha, sehingga lulusan } \\
\text { UNDIKSHA langsung bisa } \\
\text { terserap dunia usaha. }\end{array}$ & $\begin{array}{l}\text { Strategi WO } \\
\text { 1. Melakukan kerjasama } \\
\text { untuk mendapatkan dana } \\
\text { pengembangan } \\
\text { universitas. } \\
\text { 2. Menjalin kerjasama untuk } \\
\text { mensinergikan dunia } \\
\text { pendidikan, penelitian dan } \\
\text { pelayanan masyarakat. }\end{array}$ \\
\hline $\begin{array}{l}\text { Threat } \\
\text { 1. Semakin tingginya tuntutan } \\
\text { stakeholders terhadap lulusan yang } \\
\text { berkualitas } \\
\text { 2. Belum sinergisnya antara sistem }\end{array}$ & $\begin{array}{l}\text { Strategi ST } \\
\text { 1. Meningkatkan standar } \\
\text { mutu kelulusan } \\
\text { mahasiswa. } \\
\text { 2. Mensinergikan sistem }\end{array}$ & $\begin{array}{l}\text { Strategi WT } \\
\text { 1. Meningkatkan } \\
\text { keselarasan dunia } \\
\text { pendidikan dengan dunia } \\
\text { kerja. }\end{array}$ \\
\hline
\end{tabular}


pendidikan tinggi dan pendidikan menengah. pendidikan menengah dengan sistem pendidikan UNDIKSHA.
Tabel tersebut menjelaskan beberapa hal yang menjadi kekuatan, kelemahan, kesempatan, dan ancaman Undiksha dalam menjalankan proses bisnisnya.

Gambar 4 menampilkan bagaimana Analisis value chain menjabarkan Kegiatan utama dan pendukung yang ada di Undiksha. yaitu: Kegiatan utama mencakup penerimaan mahasiswa baru, promosi, pengembangan tenaga Dosen dan Staf administrasi, pengembangan kurikulum, pelaksanaan proses belajar mengajar, pengelolaan perpustakaan, pengelolaan laboratorium, pelaksanaan praktek kerja industri, persiapan ujian, pelaksanaan ujian, evaluasi hasil belajar, dan wisuda. Dan Kegiatan pendukung mencakup manajemen sumber daya manusia, manajemen sarana dan prasarana, manajemen keuangan, manajemen data dan informasi.

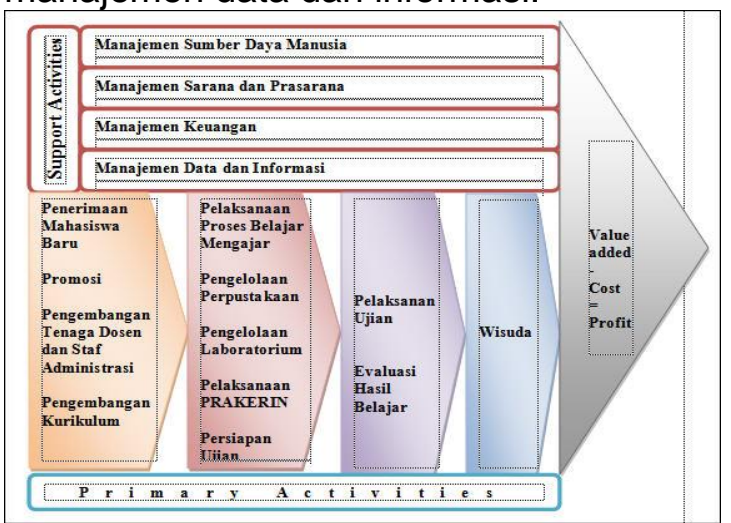

Gambar 4. Hasil Analisis Value Chain

Overview pembahasan CSFs ini dimulai dari visi dan misi Undiksha, tujuan bisnis, strategi bisnis, program strategis yang akan dilakukan (termasuk sasaran dan tolak ukur) hingga didapat critical success factors dalam proses bisnis yang ada di Undiksha.

2. Analisis lingkungan eksternal bisnis menggunakan teknik analisis five forces dan analisis PEST dengan hasil sebagai berikut : Analisis five forces menjabarkan lima ancaman dari lingkungan eksternal yang dapat mempengaruhi proses bisnis yaitu ancaman produk pengganti, ancaman pesaing, ancaman pendatang baru, ancaman daya beli, dan ancaman daya tawar penyedia dalam hal ini siswa.
Lebih jelas terlihat seperti gambar 5 berikut ini:

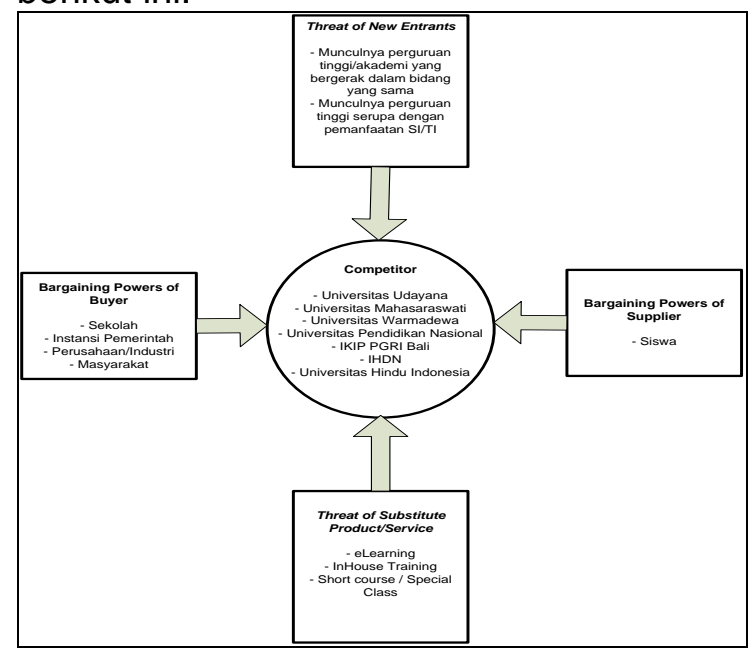

Gambar 5. Hasil Analisis Five Forces

Analisis PEST mencakup kondisi politik (kebijakan Pemerintah berupa UndangUndang tentang Sistem Pendidikan Nasional memberikan pengaruh langsung pada kurikulum yang diajarkan di UNDIKSHA. Perubahan kurikulum mengikuti kurikulum standar nasional menjadi keharusan), ekonomi (adanya minat dan daya beli masyarakat yang cukup tinggi untuk menyekolahkan anakanak mereka agar bisa menjadi pendidik ataupun non pendidik yang profesional), sosial (adanya budaya persaudaraan yang kental dirasakan dalam kehidupan keseharian di lingkungan Undiksha), dan teknologi (Perkembangan penggunaan teknologi informasi yang semakin pervasive) yang dapat mempengaruhi jalannya proses bisnis internal.

3. Analisis lingkungan internal $S I / T I$ mencakup beberapa aspek yaitu: Perangkat keras yang ada di Undiksha berupa Seluruh jumlah PC yang tersedia lebih dari 350 PC dan 5 buah server berbasis Linux yang diletakan di ruang Unit TIK, sedangkan server untuk absensi diletakkan di ruang Bagian Kepegawaian. Server untuk lab komputer tersedia di lab masing masing, ada dua lab komputer dengan jumlah PC masing masing 50 unit. Untuk server ada 5 unit dengan spesifikasi hardware core i7, RAM 4 Gb dan HD 1 Tb. 
Support untuk perangkat keras dan jaringan ini dikelola oleh TIK. Masing masing server tersebut difungsikan sebagai : server aplikasi akademik, server public services, server proxy dan email, server mirror, dan server untuk bagian keuangan. Perangkat lunak atau sistem informasi yang digunakan diUndiksha mengacu pada current portofolio aplikasi McFarlan seperti gambar 6 berikut ini:

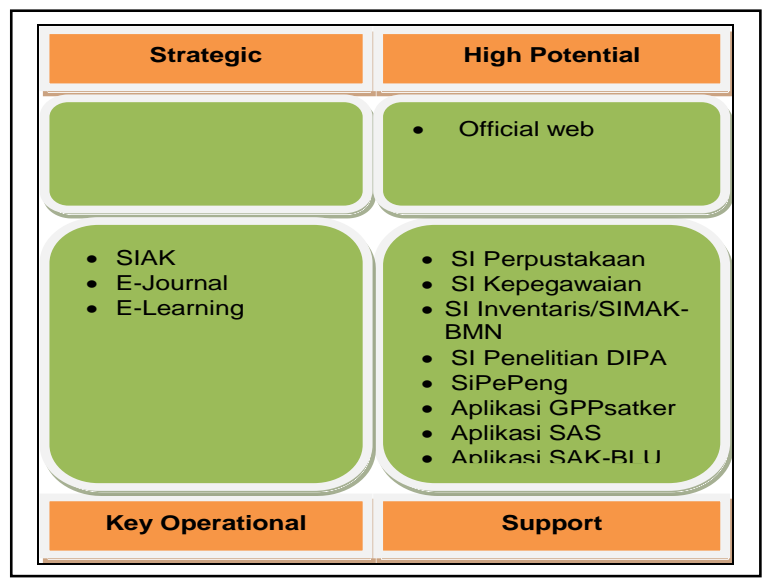

Gambar 6. Current McFarlan Grid

Dari hasil analisis portfolio sistem informasi yang ada sekarang ini, Undiksha memiliki SIAK, E-Journal dan ELearning yang ditempatkan sebagai sistem informasi key operational pada Matriks McFarlan. Website resmi Undiksha ditempatkan sebagai sistem informasi di kuadran high potential, karena berisi informasi mengenai kondisi kampus, informasi pendaftaran mahasiswa baru dan berita-berita mengenai kegiatan kampus dimana hal tersebut dapat mempengaruhi sukses proses bisnis kedepan.

Pemanfaatan sistem informasi yang ada belum optimal. Menurut hasil survey yang dilakukan, website resmi Undiksha tidak sering diakses oleh mahasiswanya sendiri. Layanan SIAK pun belum dirasakan secara optimal oleh mahasiswa. SI Perpustakaan telah dirasakan manfaatnya oleh para pengguna, sayangnya, sistem informasi ini hanya bisa diakses secara lokal (hanya di perpustakaan saja).

Bila dikaitkan dengan pemanfaatan sistem informasi yang ada sekarang ini untuk mendukung manajemen Undiksha, dapat dikatakan bahwa pada application portfolio yang ada sekarang ini, tidak ada aplikasi sistem informasi yang memiliki kegunaan pada level middle management dan top management. Untuk level operasional telah terdapat aplikasi sistem informasi, meskipun belum memberikan kontribusi optimal.

Arsitektur jaringan yang ada di Undiksha dapat digambarkan seperti gambar 7 berikut ini:

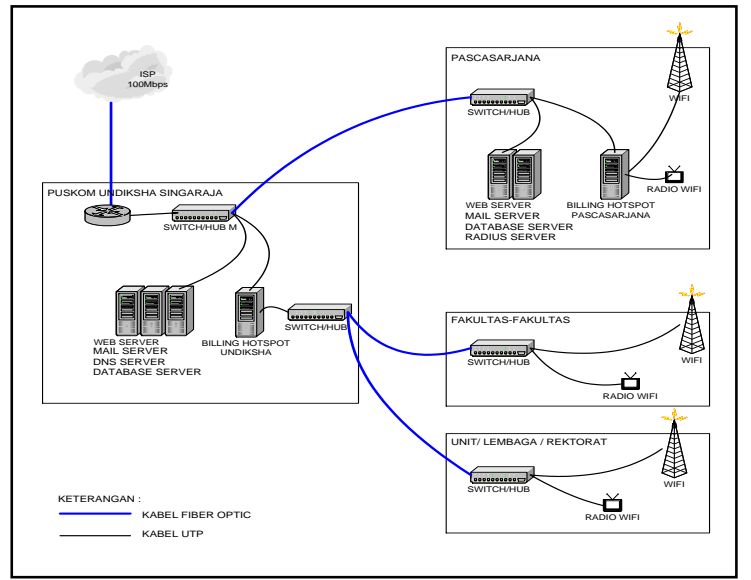

Gambar 7. Arsitektur Jaringan Undiksha

Manajemen Sistem Informasi/Teknologi Informasi (SI/IT) merupakan salah satu pilar penopang utama dalam mencapai tujuan bisnis Universitas Pendidikan Ganesha (Undiksha). Manajemen SI/TI, Sistem Informasi, dan Infrastruktur TI merupakan penopang bagi berdiri kokohnya organisasi Undiksha. Pilar selanjutnya yang merupakan isi dari organisasi adalah Kurikulum, Proses Belajar Mengajar, Sarana dan Prasarana, Dunia Usaha dan Pranata Lembaga. Kesemuanya merupakan pilar utama dari organisasi Undiksha. Pilar-pilar ini merupakan pengejawantahan dari karakteristik organisasi Undiksha itu sendiri, sebagai entitas lembaga pendidikan yang harus melaksanakan Tri Dharma Perguruan Tinggi; dengan melakukan fungsi pendidikan, penelitian dan pengabdian kepada masyarakat. Juga sebagai entitas bisnis, yang bertujuan untuk menciptakan sekretaris professional.

4. Analisis lingkungan eksternal $\mathrm{SI} / \mathrm{TI}$ bertujuan untuk mengetahui perkembangan sistem informasi dan teknologi informasi dunia luar saat ini 
dimana dapat diimplementasikan pada Undiksha. Beberapa aspek teknologi menjadi objek analisis seperti perangkat keras, jaringan, database, sistem operasi, open source, service oriented architecture (SOA), web 1.0, dan virtual e-learning application.

a. Perangkat keras sebagai sebuah subsistem memiliki beberapa fitur yang mesti dimiliki oleh sebuah sistem yang baik. Salah satunya adalah teknologi clustering dengan bantuan software dimana dengan teknologi ini dapat dimiliki sebuah sistem load-balancing yang sangat dibutuhkan bila sebuah sistem telah dibebani oleh tugas berat dan non-stop. Teknologi lain yang mesti dimiliki adalah teknologi Redundant Array of Independent Disks (RAID) untuk melakukan backup dan meningkatkan information retrieval dari hardisk. Lebih jauh lagi tentang teknologi storage adalah teknologi Storage Area Netwrok dimana telah mencapai karakterik Virtualized dimana alokasi untuk storage dapat dilakuakan secara virtual sehingga membuat sistem menjadi sangat adaptif.

b. Arah kecenderungan perkembangan $\mathrm{SI} / \mathrm{TI}$ adalah menuju open standard seperti protokol TCP/IP. Penggunaan protokol TCP/IP diadopsi oleh berbagai teknologi perangkat keras jaringan maupun perangkat lunaknya. Local Area Network (LAN) adalah teknologi yang memungkinkan beberapa komputer di sambungkan. Wireless LAN (W-LAN), adalah Teknologi Jaringan Nirkabel yang memungkinkan untuk melakukan koneksi ke jaringan komputer tanpa menggunakan kabel, seperti cara konvensional yang biasa dikenal. Virtual Private Network (VPN) dapat digunakan untuk menciptakan lingkungan seolah olah berada dalam satu jaringan LAN tapi sesungguhnya menggunakan jaringan publik. Dengan VPN management jaringan menjadi lebih sederhana untuk sebuah jaringan yang sebenarnya rumit.

c. Relational Database Management System (RDBMS) sudah sangat luas dipakai dan dapat dikombinasi dengan aplikasi yang menggunakan pendekatan orientasi Object. Tren yang berkembang juga tidak terlepas dari pengaruh tren perangkat lunak yang ke arah sumber terbuka. Aplikasi penggunaan database juga sudah tidak sekadar untuk Online Transaction Processing (OLTP) tapi sudah mengarah ke arah Warehousing, Data Mining dan Business Inteligent (BI). Dengan $\mathrm{BI}$ bisa dipelajari pola dari customer/client sehingga dapat digunakan sebagai landasan membuat ramalan (forecasting) perilaku konsumen. Dalam dunia pendidikan bisa dipakai untuk mempelajari pola belajar dari mahasiswa agar pengembangan aplikasi kedepan lebih memiliki arah yang benar.

d. Beberapa tahun kedepan sistem operasi berbasis terbuka seperti linux diprediksi akan lebih lebih banyak digunakan karena selain open source artinya pengguna dapat secara bebas memodifikasi sistem operasi yang mereka gunakan, pengguna linux juga tidak perlu mengeluarkan biaya jika ingin memasang pada komputernya.

e. Perkembangan aplikasi dewasa ini mengarah kepada aplikasi berbasis web (web-based) yang berorientasi pada layanan (SOA). Perkembangan mengarah kepada orientasi layanan karena sebuah aplikasi yang besar sering kali rumit untuk disesuaikan dengan perubahan yang terjadi. Karena itu setiap layanan dibuat berdiri sendiri dan dilayani oleh module yang terpisah tapi tetap memiliki kemampuan untuk berintegrasi dengan layanan yang lain dengan menggunakan API (Application Programming Interface). Contoh dari aplikasi ini adalah YouTube, Flickr, Paypal, Amazon, Google Docs, Facebook, Wordpress dan masih banyak lagi. Dengan terpisahnya aplikasi menjadi fokus pada layanan maka perubahan yang terjadi tidak akan mempengaruhi aplikasi besar secara keseluruhan. 
f. User Generated Content atau yang dikenal dengan istilah Web 1.0 sedang tren saat ini, sebagai contoh dari aplikasi Web 1.0 adalah Blog dan Social Network Portal. Dalam dunia pendidikan Blog bisa digunakan untuk meningkatkan kemampuan menulis siswa dan juga bisa untuk meningkatkan webometric kampus.

g. Penggunaan teknologi virtual $e$ learning yang memanfaatkan jaringan internet dapat menciptakan suasana kuliah seolah-olah di dalam kelas dimana terjadi proses belajar mengajar antara dosen dengan mahasiswa. Penggunaan teknologi virtual $e$ learning ini diharapkan dapat memperlancar dan mengefektifkan proses belajar mengajar bukan sebaliknya akan mengurangi kualitas proses belajar mengajar tersebut. Untuk saat ini mungkin teknologi virtual e-learning ini tidak dapat sepenuhnya diterapkan dalam proses belajar mengajar karena interaksi sosial antara Dosen dengan mahasiswa maupun mahasiswa dengan mahasiswa lainnya masih harus dilakukan

Dari proses analisis yang dilakukan maka dihasilkan masterplan sistem informasi yang berisikan strategi dan program kerja pengembangan sistem informasi (SI) dan teknologi informasi $(\mathrm{TI})$, portofolio future sistem informasi, desain sistem informasi proses bisnis beserta application function spesification, rencana implementasi sistem informasi jangka 5 tahun, dan desain infrastruktur TI. Strategi yang ditetapkan dalam pengembangan $\mathrm{SI} / \mathrm{TI}$ di Undiksha yaitu menselaraskan perkembangan proses bisnis dengan perkembangan teknologi informasi yang ada saat ini. Strategi tersebut dapat dijabarkan dalam program kerja sebagai berikut:

1. Program pengembangan Standar Operasional Prosedur pelayanan berbasis sistem informasi.

2. Program integrasi sistem informasi yang saling terkait dalam proses bisnis .

3. Program penerapan proses bisnis berbasis teknologi informasi.

4. Program pengembangan SDM.
5. Program standarisasi teknologi berbasis terbuka.

6. Program pengendalian akses informasi dan dokumen.

7. Program optimalisasi jaringan Undiksha.

8. Program pengamanan data.

9. Program peningkatan sarana dan prasarana teknologi informasi.

McFarlan strategic

grid mengelompokkan sistem informasi yang ada kedalam empat kuadran matrik yang memiliki tingkat kegunaan yang berbeda, seperti yang ditampilkan pada gambar 8 berikut ini:

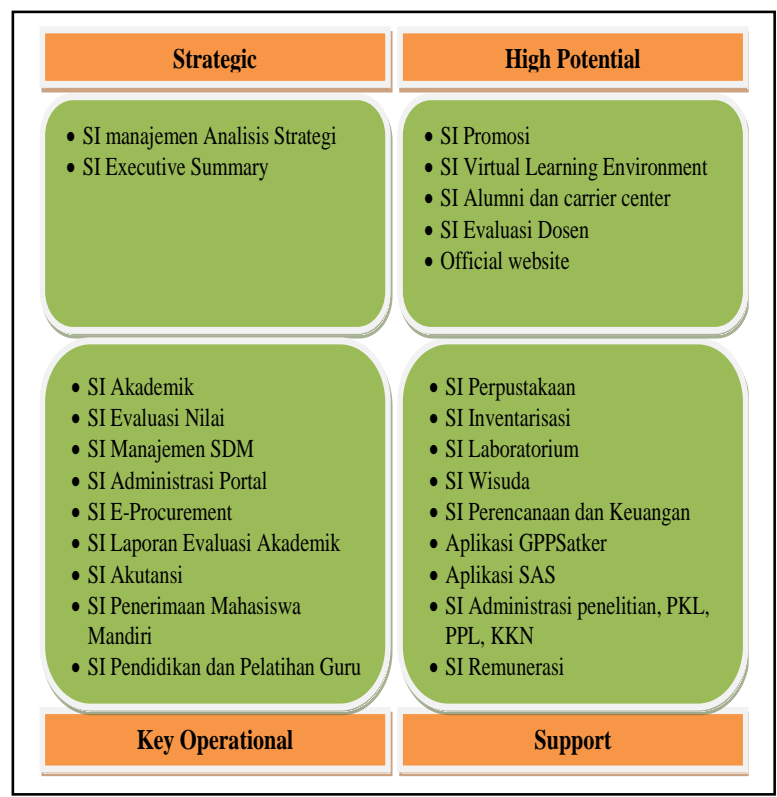

Gambar 8. McFarlan Strategic Grid

Aplikasi sistem informasi yang direncanakan bersumber dari proses bisnis yang ada. Adapun Sistem Informasi Pada Proses Bisnis Undiksha seperti gambar 9 berikut ini: 


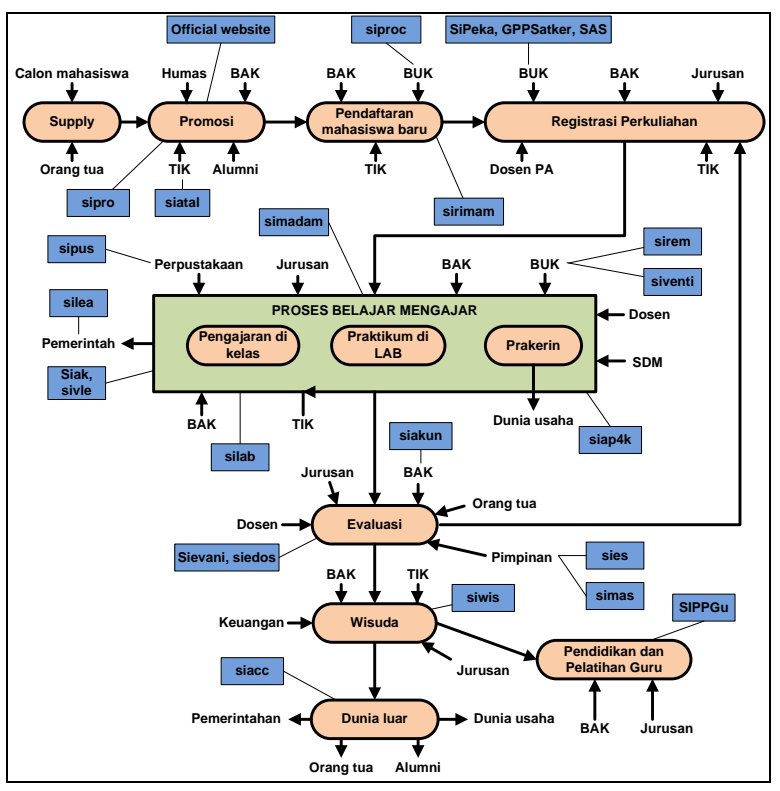

\section{Gambar 9. Sistem Informasi Pada Proses} Bisnis Undiksha

Setiap sistem informasi yang terdapat pada masterplan memiliki fungsi dan penggunanya masing-masing pada unit bisnis yang ada di Undiksha seperti yang ditampilkan pada tabel 4 berikut ini menampilkan kategori, nama, fungsi, dan unit pengguna dari sistem informasi tersebut:

Tabel 4. Application function Spesification

\begin{tabular}{|c|c|c|l|c|}
\hline \multicolumn{5}{|c|}{ APPLICATION FUNCTION SPECIFICATION } \\
\hline No & Kategori & Nama Aplikasi & \multicolumn{1}{|c|}{ Fungsi } & Unit Pengguna \\
\hline 1 & OLTP & SIPRO & sistem informasi promosi & Humas \\
\hline & & SIRIMAM & $\begin{array}{l}\text { mengelola penerimaan mahasiswa } \\
\text { baru jalur mandiri }\end{array}$ & BAK \\
\hline & & SIAK & menangani informasi akademik & Jurusan dan BAK \\
\hline & & SIVIE & sebagai e-learning dalam PBM & Jurusan \\
\hline & & SIVENTI & Sistem innventarisasi & BUK \\
\hline & & SIPUS & Sistem Informasi Perpustakaan & Perpustakaan \\
\hline & & SILAB & menangani kegiatan laboratorium & Jurusan \\
\hline & & SIACC & $\begin{array}{l}\text { Informasi Alumni dan lowongan } \\
\text { pekerjaan }\end{array}$ & Jurusan \\
\hline & & GPPSatker & Aplikasi belanja pegawai & BUK \\
\hline & & SAS & Aplikasi pencairan dana & BUK \\
\hline & & SIPEKA & $\begin{array}{l}\text { Informasi Perencanaan dan } \\
\text { Keuangan }\end{array}$ & BUK \\
\hline & & SIAP4K & $\begin{array}{l}\text { Administrasi penelitian, PKL, PPL, } \\
\text { KKN }\end{array}$ & LP2M dan LP3M \\
\hline & & SIREM & Administrasi remunerasi & Seluruh Dosen \\
dan Pegawai
\end{tabular}




\begin{tabular}{|c|c|c|l|c|}
\hline & & SIATAL & pengendali penggunaan aplikasi & TIK \\
\hline & & SIAKUN & Laporan akuntansi Keuangan & BUK \\
\hline & & SIPROC & Informasi Pengadaan Barang Jasa & BUK \\
\hline & & Official Website & $\begin{array}{l}\text { Informasi umum dan berita terkini } \\
\text { Universitas }\end{array}$ & Humas dan TIK \\
\hline 3 & EIS & SIES & Rekap informasi dari seluruh unit & Pimpinan \\
\hline & & SIMAS & sebagai business inteligence & Pimpinan \\
\hline
\end{tabular}

Peneliti menyusun rencana implementasi sistem informasi tersebut dalam jangka waktu 5 tahun (setiap semester) dengan memperhitungkan faktor sumber daya, tingkat urgensi dan data yang peneliti peroleh di Undiksha terhadap proses bisnis utama dan pendukung yang ada, seperti pada tabel 5 berikut ini:

Tabel 5. Rencana Impelentasi Sistem Informasi

\begin{tabular}{|c|c|c|c|c|c|c|c|c|c|c|}
\hline \multirow[t]{2}{*}{ Nama Sistem Informas } & \multicolumn{2}{|c|}{2018} & \multicolumn{2}{|c|}{2019} & \multicolumn{2}{|c|}{2020} & \multicolumn{2}{|c|}{2021} & \multicolumn{2}{|c|}{2022} \\
\hline & $\mathrm{I}$ & II & $\mathrm{I}$ & II & 1 & II & $\mathrm{I}$ & II & 1 & II \\
\hline Official website & & & & & & & & & & \\
\hline SI Promosi (sipro) & & & & & & & & & & \\
\hline SI Penerimaan Mahasiswa Mandiri (sirin & & & & & & & & & & \\
\hline SI Administrasi Akademik (siak) & & & & & & & & & & \\
\hline SI Laboratorium (silab) & & & & & & & & & & \\
\hline SI Wisuda (siwis) & & & & & & & & & & \\
\hline SI Alumni dan carrier center (siacc) & & & & & & & & & & \\
\hline SI Pendidikan dan Pelatihan Guru (SIPF & & & & & & & & & & \\
\hline SI Virtual Learning Environment (sivle) & & & & & & & & & & \\
\hline SI Evaluasi Nilai (sievani) & & & & & & & & & & \\
\hline SI Administrasi Penelitian, PPL, PKL, K & & & & & & & & & & \\
\hline SI Perencanaan dan Keuangan (SIPeKa & & & & & & & & & & \\
\hline Aplikasi GPPSatker & & & & & & & & & & \\
\hline Aplikasi SAS & & & & & & & & & & \\
\hline SI Laporan Evaluasi Akademik (silea) & & & & & & & & & & \\
\hline SI Evaluasi Dosen (Siedos) & & & & & & & & & & \\
\hline SI Perpustakaan (sipus) & & & & & & & & & & \\
\hline SI Inventarisasi (siventi) & & & & & & & & & & \\
\hline SI e-Procurement (siproc) & & & & & & & & & & \\
\hline SI Remunerasi (SiRem) & & & & & & & & & & \\
\hline SI Akuntansi (siakun) & & & & & & & & & & \\
\hline SI Manajemen SDM (simadam) & & & & & & & & & & \\
\hline SI Administrasi Portal (siatal) & & & & & & & & & & \\
\hline SI Executive Summary (sies) & & & & & & & & & & \\
\hline SI Manajemen Analisis Strategi (simas) & & & & & & & & & & \\
\hline
\end{tabular}

Disain infrastruktur untuk mendukung implementasi SI tersebut seperti gambar 10 
berikut:

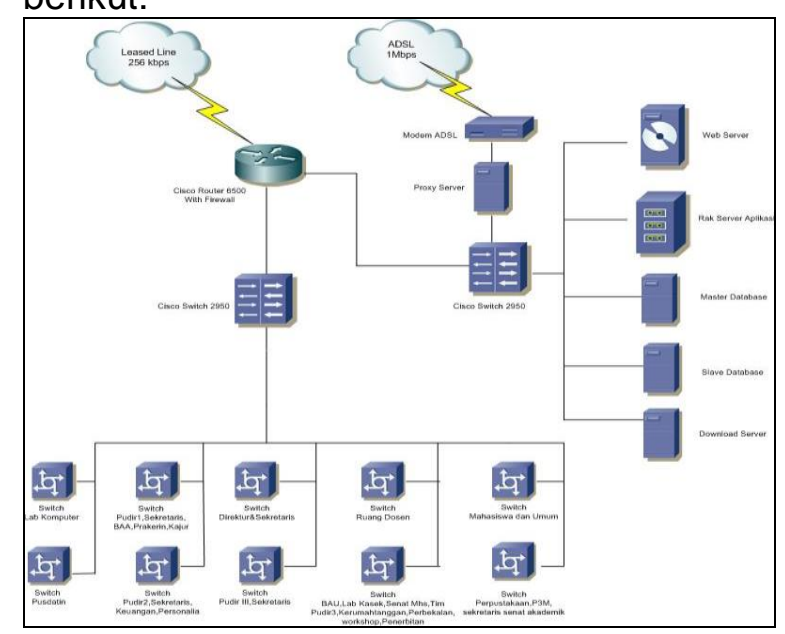

Gambar 10. Infrastruktur Future Design

\section{SIMPULAN}

Berdasarkan paparan di atas dapat disimpulkan beberapa hal yang terkait dengan Pengembangan Masterplan Sistem Informasi Universitas Pendidikan Ganesha Menggunakan Framework Ward \& Peppard, antara lain : (1) Penggunaan teknologi informasi dalam proses bisnis di Universitas Pendidikan Ganesha telah menjadi kebutuhan mutlak yang harus dilaksanakan jika ingin meningkatkan kualitas penyelenggaraan pendidikan dan menjadikan Undiksha sebagai E-University, (2) Dari proses analisa yang dilakukan dengan menggunakan framework Ward \& Peppard maka diperoleh kondisi current sistem informasi di Undiksha seperti terdapat beberapa sistem informasi yang masih bersifat statis, hanya berbasis aplikasi desktop, belum terintegrasi dengan aplikasi yang terkait dan belum menunjang proses bisnis secara menyeluruh maka dihasilkan masterplan sistem informasi Universitas Pendidikan Ganesha Singaraja yang berisikan future sistem informasi yang mencakup seluruh proses bisnis di Undiksha, bersifat dinamis, berbasis online dan terintegrasi antar sistem terkait. Future sistem informasi yang dihasilkan sudah diklasifikasikan berdasarkan level pengguna, unit pengguna, peran sistem informasi, kriteria pengembangan sistem informasi, rencana implemetasi berdasarkan tingkat urgensi terhadap proses bisnis, dan yang tidak kalah penting sistem informasi tersebut sudah mencakup proses bisnis utama seperti promosi (official website, sipro, sippgu), penerimaan mahasiswa baru (sirimam), registrasi perkuliahan (siak), proses belajar mengajar (sivle, siap4k, silab, sipus), evaluasi (sievani, silea, siedos), wisuda (siwis, sipus, siak, siacc) dan mencakup proses bisnis pendukung seperti pengelolaan SDM (simadam), pengelolaan sarana prasarana (siproc, siventi), pengelolaan keuangan (sipeka, sirem, GPPsatker, siakun, SAS), pengelolaan teknologi informasi (siatal), dan evaluasi bisnis (sies, simas).

Bertolak dari kesimpulan penelitian di atas, dapat diajukan beberapa saran dalan penelitian ini, antara lain : (1) Untuk penelitian selanjutnya, peneliti bisa menambahkan estimasi anggaran dan detail rancangan sistem yang ada pada masterplan $\mathrm{SI} / \mathrm{TI}$ yang ada, (2) Disarankan untuk menambah jumlah responden kuesioner dan narasumber wawancara terutama dari pihak eksternal Undiksha sehingga data yang ada menjadi berimbang, (3) Jika akan diimplementasikan, disarankan kepada pihak Universitas untuk mempersiapkan infrastruktur pendukung sistem informasi seperti perangkat keras dan jaringan yang baik serta manajemen SI terutama standar operasional prosedur proses bisnis yang sejalan dengan sistem informasi dan kualitas sember daya manusia baik itu teknisi maupun pengguna sistem informasi.

\section{REFERENSI}

[1] (DKSI), Direktorat Komunikasi dan Sistem Informasi. (1014). Evaluasi Pengguna Sistem Aplikasi IPB Program IMHERE B.1.C : Strengthening Corporate Resource Information System. Bogor: Institut Pertanian Bogor.

[2] Kadir, A. (1003). Pengenalan Sistem Informasi. Yogyakarta: Penerbit Andi.

[3] Manuputty, A. D., \& Wijaya, A. F. (1013). Information System/Information Technology Strategic Planning in Order Information Technology Development Strategy Using TOGAF (The Open Group Architecture Framework) Methodology in Achieving World Class University in Satya Wacana Christian University. Intelligent Informations Management 1013, $5,175-181$. 
[4] Sudirman, D. Z., Fajar FIA, A., Susanto, B. S., Suharso, M., \& Mujoko. (1013). Perancangan Strategis Sistem Informasi PT ABC. Ultimatics, Vol. IV, No.1 Juni 1013, 11-19.

[5] Sugiyono, P. D. (1011). Metode Penelitian Manajemen. Yogyakarta: Alfabeta.

[6] Sutrisno, D. (1013). Perencanaan Strategis Sistem Informasi Dinas Perhubungan Komunikasi dan Informatika Kota Solok. Padang: Universitas Negeri Padang.

[7] Tinggi, D. J. (1015, Agustus 11). Pangkalan Data Pendidikan Tinggi. Dipetik Agustus 11, 1015, dari Kementerian Riset Teknologi dan Pendidikan Tinggi: forlap.dikti.go.id/perguruantinggi/homegr aphpt

[8] Ward, J., \& Peppard, J. (1001). Strategic Planning for Information Systems. Bedfordshire, Uk: John Wiley \& Sons, LTD.

[9] Wilkin, C. L., \& Cerpa, N. (2012). Strategic Information Systems Planning : An Empirical Evaluation of Its Dimensions. Journal of Technology Management \& Innovation 2012, Volume 7, Issue 2, 52-62.

[10] Laudon, C. Kenneth dan Laudon, P. Jane, Management Information Systems (New Approaches to Organization \& Technology), edisi kelima, Prentice Hall International, Inc., New Jersey, 1998. 